\title{
Criação de mapas de prescrição de fertilizantes por meio de krigagem
}

\section{Henrique L. Varanda*, Lucas R. do Amaral, Agda L. G. Oliveira}

\section{Resumo}

O seguinte trabalho teve o objetivo de avaliar o desempenho de quatro pacotes geoestatísticos na modelagem semivariográfica e na qualidade dos mapas interpolados, com o intuito de descobrir se existiriam diferenças de desempenho das estimativas espaciais. Porém, por mais que houvesse diferenças visuais entre os mapas interpolados obtidos, essas diferenças não foram suficientes para, estatisticamente, apontar o melhor pacote para uso em agricultura de precisão.

\section{Palavras-chave:}

Agricultura de precisão, Geoestatística, Krigagem

\section{Introdução}

A agricultura de precisão assume que as lavouras não são uniformes, tanto no tempo, quanto no espaço. Uma maneira de mostrar as variações existentes está na criação de mapas interpolados (de atributos do solo, produtividade, dentre outros), os quais são construídos a partir de amostragem realizadas no campo e com auxílio de Sistemas de Informação Geográficas (SIGs). Porém, existem diversos softwares para realização desta tarefa, os quais possuem configurações próprias, o que pode gerar resultados discrepantes. Portanto, o trabalho teve o objetivo de avaliar o desempenho de 4 pacotes geoestatísticos na qualidade de interpolação de mapas. Foram gerados 6 campos virtuais de 100 ha para realização do trabalho, sendo realizada uma amostragem em grade regular, também virtual, com 100 $\mathrm{m}$ de espaçamento entre os pontos, totalizando 100 amostras. Os 6 campos foram analisados geoestatisticamente em 4 pacotes diferentes: geoR e gstat, ambos em ambiente R, Geostatiscal Analyst (ArcGIS®) e Vesper. Além disso, diferentemente dos softwares comerciais, os pacotes em $\mathrm{R}$ permitem o uso de mais de um método para ajuste do semivariograma, assim testamos o Método dos Momentos (MoM) e o Método da Máxima Verossimilhança Restrita (REML). Com isso, foram interpolados 36 mapas por krigagem.

\section{Resultados e Discussão}

A comparação dos mapas de referência (campos virtuais) com os mapas interpolados, por meio do teste $F$, mostrou que os pacotes de interpolação possuem a mesma precisão (Figura 1).

Mesmo sem diferenças estatísticas, uma vez que cada simulação de campo virtual gera comportamento espacial diferenciado, houveram diferenças visuais entre os mapas interpolados (Figura 2). Isso ocorreu porque os pacotes tendem a estimar os valores de locais não amostrados de forma diferente, alguns suavizando os dados preditos (menor amplitude), como ilustrado no mapa do Vesper (Figura 2). Além disso, a modelagem semivariográfica também sofre variações, podendo entregar resultados diferentes. Assim, futuros estudos devem variar a densidade amostral testada, trabalhar com maior número de realizações (repetições) dos campos virtuais e com diferentes efeitos direcionais (comportamento não estacionário) a fim de avaliar a superioridade dos diversos pacotes e softwares disponíveis para interpolação por krigagem e dos métodos de modelagem semivariográfica utilizados.

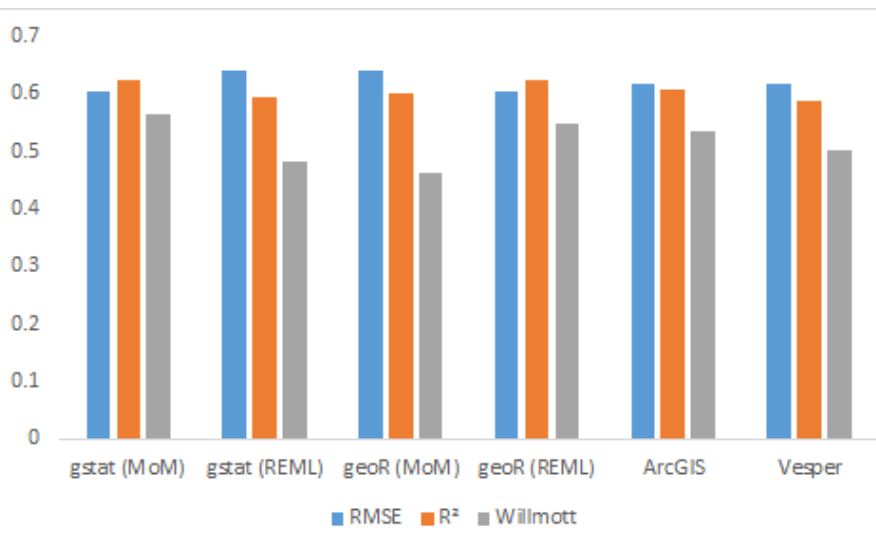

Figura 1. Comparação das interpolações realizadas pelos diferentes pacotes e o campo virtual. As barras verticais representam os valores médios das estatísticas avaliadas para os seis campos virtuais. RMSE: Raíz Quadrática do Erro Médio; R ${ }^{2}$ : Coeficiente de Determinação e o Índice de Concordância de Willmott.
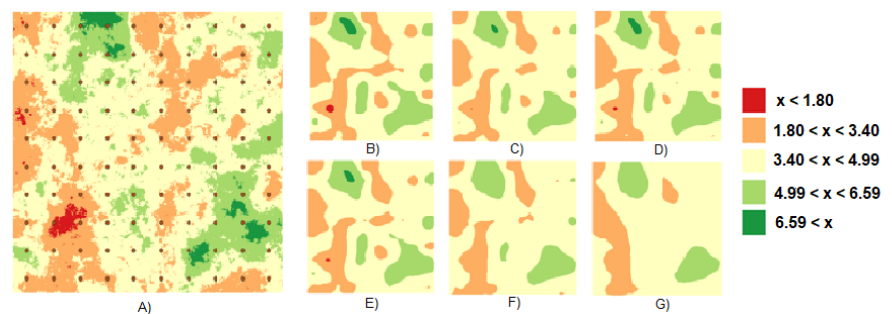

Figura 2. (A) Exemplo de campo virtual, mostrando a grade amostral utilizada e os respectivos mapas interpolados obtidos nos pacotes, sendo eles: (B) gstat (MoM), (C) geor (MoM), (D) ArcGIS, (E) geor (REML), (F) gstat (REML) e (G) Vesper.

\section{Conclusões}

Apesar das diferenças visuais existentes entre os mapas interpolados, o uso de diferentes pacotes para análise geoestatística (dadas as condições de número de campos virtuais, interpolações e densidade amostral impostas no trabalho), mostrou desempenho semelhante, não sendo possível afirmar qual oferece o melhor desempenho nas interpolações por krigagem.

\section{Agradecimentos}

Agradeço ao PIBIC pela concessão da bolsa e ao GITAP, em especial à doutoranda Maiara Pusch pelo auxílio prestado no decorrer da Iniciação Científica. 